\title{
CARACTERIZAÇÃO QUÍMICA E ATIVIDADE MUTAGÊNICA DO ÓLEO ESSENCIAL DE Lippia alba
}

\author{
Thammyres de Assis Alves ${ }^{1}$ \\ Carolaine dos Santos Ferreira ${ }^{2}$ \\ Rondinelle Giordane da Costa ${ }^{3}$ \\ Maikon Keoma da Cunha Henrique ${ }^{4}$ \\ Milene Miranda Praça-Fontes ${ }^{5}$ \\ Patrícia Fontes Pinheiro ${ }^{6}$
}

Resumo: Os óleos essenciais são substâncias voláteis que vêm despertando interesse no setor agrícola, devido o grande potencial que possuem no controle de pragas. Assim, objetivo deste trabalho foi determinar a composição química do óleo essencial de folhas de Lippia alba e avaliar o seu potencial mutagênico. Para isso, o óleo essencial foi obtido por hidrodestilação, utilizando um aparelho do tipo Clevenger, seus constituintes químicos foram analisados por meio da cromatografia em fase gasosa com detector de ionização de chama (CG-DIC) e de espectrometria de massas (CG-EM). Os compostos majoritários encontrados foram: geranial (29,83\%), neral (20,71\%) e óxido de cariofileno (19,26\%). A toxicidade do óleo essencial de L. alba foi avaliado em sementes de Lactuca sativa. O óleo essencial de L. alba inibiu $100 \%$ o crescimento radicular das sementes de $L$. sativa nas concentrações de $0,720 \%$ e $0,360 \%\left(\mathrm{~m} \mathrm{v}^{-1}\right)$. Nas outras concentrações testadas (0,180\%, 0,090\%, 0,045\%), o óleo essencial apresentou um decréscimo no efeito de inibição conforme diminuição de sua concentração. Logo, o óleo essencial de L. alba possui potencial a ser usado como bioherbicida.

Palavras-chave: Bioherbicida; Erva-cidreira; Composição química; Constituintes voláteis; Mutagênese.

\footnotetext{
${ }^{1}$ Mestranda em Genética e Melhoramento/Universidade Federal do Espírito Santo, Centro de Ciências Agrárias e Engenharias, Brasil, Alegre - ES. E-mail: thammyresalves@gmail.com.

2 Graduanda em Química Licenciatura/ Universidade Federal do Espírito Santo, Centro de Ciências Agrárias e Engenharias, Brasil, Alegre - ES. E-mail: carolrock.felix@hotmail.com.

${ }^{3}$ Mestrando em Genética e Melhoramento/Universidade Federal do Espírito Santo, Centro de Ciências Agrárias e Engenharias, Brasil, Alegre - ES. E-mail: rondgiocosta@gmail.com.

4 Graduando em Engenharia Florestal/ Universidade Federal do Espírito Santo, Centro de Ciências Agrárias e Engenharias, Brasil, Alegre - ES. E-mail: maikond2@gmail.com.

5 Professora Adjunta/Universidade Federal do Espírito Santo, Centro de Ciências Exatas, Naturais e da Saúde CCENS -UFES/Departamento de Biologia, Alegre-ES. E-mail: milenemiranda@yahoo.com.br.

${ }^{6}$ Professora Adjunta/Universidade Federal do Espírito Santo, Centro de Ciências Exatas, Naturais e da Saúde CCENS -UFES/Departamento de Química, Alegre-ES. E-mail: patriciafontespinheiro@yahoo.com.br.
} 